\title{
Ecological niche modelling and differentiation between Rhodnius neglectus Lent, 1954 and Rhodnius nasutus Stål, 1859 (Hemiptera: Reduviidae: Triatominae) in Brazil
}

\author{
Taíza Almeida Batista', Rodrigo Gurgel-Gonçalves²/+ \\ ²Laboratório de Zoologia, Curso de Ciências Biológicas, Universidade Católica de Brasília, Brasília, DF, Brasil \\ ${ }^{2}$ Laboratório de Parasitologia Médica e Biologia de Vetores, Faculdade de Medicina, Área de Patologia, Universidade de Brasília, \\ Asa Norte, Brasília 70.910-900, DF, Brasil
}

Ecological niche modelling was used to predict the potential geographical distribution of Rhodnius nasutus Stål and Rhodnius neglectus Lent, in Brazil and to investigate the niche divergence between these morphologically similar triatomine species. The distribution of R. neglectus covered mainly the cerrado of Central Brazil, but the prediction maps also revealed its occurrence in transitional areas within the caatinga, Pantanal and Amazon biomes. The potential distribution of R. nasutus covered the Northeastern Region of Brazil in the semi-arid caatinga and the Maranhão babaçu forests. Clear ecological niche differences between these species were observed. R. nasutus occurred more in warmer and drier areas than R. neglectus. In the principal component analysis PC1 was correlated with altitude and temperature (mainly temperature in the coldest and driest months) and PC2 with vegetation index and precipitation. The prediction maps support potential areas of co-occurrence for these species in the Maranhão babaçu forests and in caatinga/cerrado transitional areas, mainly in state of Piaui. Entomologists engaged in Chagas disease vector surveillance should be aware that $\mathrm{R}$. neglectus and $\mathrm{R}$. nasutus can occur in the same localities of Northeastern Brazil. Thus, the identification of bugs in these areas should be improved by applying morphometrical and/or molecular methods.

Key words: Rhodnius neglectus - Rhodnius nasutus - GARP - geographical distribution - ecological niche modelling - Brazil

Ecological niche modelling (ENM) is a methodological approach that generates geographical distribution models for species. It has been a useful tool in studies on zoogeographical distribution patterns (Anderson et al. 2003, Tsoar et al. 2007). In vector studies, ENM suggests potential areas of vector occurrence and consequently, risk areas of pathogen transmission (Peterson 2006). This approach has already been used to analyse the geographical distribution of some triatomine species (Costa et al. 2002, Peterson et al. 2002, López-Cárdenas et al. 2005, Gurgel-Gonçalves \& Cuba 2009), thus contributing to epidemiological studies on Chagas disease.

Rhodnius neglectus Lent, 1954 is a common (although non-endemic) species of the cerrado biome in Central Brazil (Gurgel-Gonçalves \& Cuba 2009). Rhodnius nasutus Stål, 1859 seems to be restricted to the Northeastern Region of Brazil in the semi-arid caatinga, including the states of Ceará (CE), Maranhão (MA), Pernambuco (PE), Piauí and Rio Grande do Norte (Lucena \& Lima-Borba 1977, Carcavallo et al. 1999, Galvão et al. 2003). These triatomines are frequently found in palm trees and bird nests in sylvatic environments, but adult specimens infected by Trypanosoma cruzi Chagas, 1909 have been invading houses in Central and North-

Financial support: FAP-DF, CNPq

+Corresponding author: rgurgel@unb.br

Received 10 August 2009

Accepted 19 November 2009 eastern Brazil (Sarquis et al. 2004, Gurgel-Gonçalves et al. 2008). The problem of reinfestation of insecticidetreated dwellings highlights the need for a better understanding of the geographical distribution and ecology of wild vector species (Guhl et al. 2009). Thus, predicting the distribution of these triatomines may improve vector surveillance strategies for Chagas disease.

$R$. neglectus and $R$. nasutus are morphologically similar triatomines, distributed in open formations with long dry seasons in Central and Northeastern Brazil, respectively. Although $R$. neglectus occurs mainly in the cerrado and $R$. nasutus in the drier caatinga, there is evidence that these two species may occur sympatrically in transitional areas between their respective core ecoregions (Abad-Franch et al. 2009). However, the geographical distribution limits of these species are still poorly known. Thus, the aims of our study were: (i) to predict the potential geographical distribution of $R$. nasutus and $R$. neglectus in Brazil using the ENM approach, (ii) to investigate the ecological niche differences between these species, (iii) to identify the environmental variables that most influence their geographical distribution and (iv) to identify potential areas of co-occurrence for $R$. nasutus and $R$. neglectus.

\section{MATERIALS AND METHODS}

Occurrence records for $R$. nasutus and $R$. neglectus - The distributional data for $R$. nasutus were obtained from Lent (1948), Lent (1954), Lucena and Lima-Borba (1977), Lent and Wygodzinsky (1979), Silveira et al. (1984), Pinto and Bento (1986), Carcavallo et al. (1999), 
Galvão et al. (2003), Sarquis et al. (2004), Dias et al. (2008), Lima and Sarquis (2008) and Abad-Franch et al. (2009). Distributional data for $R$. neglectus were obtained from Gurgel-Gonçalves and Cuba (2009). Geographical coordinates of the municipality administrative centre were obtained from the Brazilian Institute of Geography and Statistics - IBGE (http://www.ibge.gov. br) database. All maps were created and edited using the software ARC VIEW (version 3.2).

ENM and niche differentiation - Among the ENM methods developed, the Genetic Algorithm for Ruleset Production (GARP) (Stockwell \& Peters 1999) has demonstrated its utility for predicting species distributions (Anderson et al. 2003). Twenty-one variables were used to generate models using the DesktopGarp application (version 1.1.6). Details about the environmental database and the software parameters used in GARP are described elsewhere (Gurgel-Gonçalves \& Cuba 2009). The $\chi^{2}$ statistic was used to calculate the probability of a random prediction being similar as the one generated by GARP. For each species we produced 100 models. The best subset procedure (Anderson et al. 2003) was used to select 10 of 100 models with the highest predictive values. These models were imported into ARC VIEW (version 3.2) and summed using the Map Calculator function in order to generate a single cumulative predictive map ranging from zero (predicted absence) to 10 (the coincidence of the 10 best models, the highest predictive agreement of presence). We considered the coincidence of the $5-10$ best models (moderate to high predictive agreement of presence) to be appropriate for describing the species' potential distribution. This procedure added a component of conservatism to the predictions of GARP, which otherwise could over-extrapolate the potential areas.

We used Student's $t$-test to compare the mean altitude, temperature, normalised difference vegetation index (NDVI) and precipitation in the areas of occurrence of $R$. neglectus and $R$. nasutus (alpha $=0.01$ ). Furthermore, we conducted a principal component analysis (PCA) with all 21 environmental variables from the occurrence areas of $R$. neglectus and $R$. nasutus. PCA reduces the dimensionality of the original set of variables with little loss of information by transforming the original variables into a new set of independent components (Foottit \& Sorensen 1992). The components that accounted for the majority of the total variance were examined and the most highly loaded variables were analysed. This approach was used to identify which environmental variables most influence the geographical distribution of these species. A scatterplot of the component scores of the species occurrence areas was created to visualise the ecological niche differences between $R$. neglectus and $R$. nasutus. PCA and Student's $t$-test were computed with Statistica ${ }^{\circledR}$ (StatSoft Inc, Tulsa, OK, USA).

\section{RESULTS}

We analysed 49 occurrence records for $R$. neglectus and 54 for $R$. nasutus. The 10 best GARP models resulting from ecological niche analysis for these species presented statistically significant $\chi^{2}$ values $(p<0.01)$, indicating that the models are quite predictive and that they summarise the ecological requirements of each species. The highest levels of commission and omission errors were observed for $R$. neglectus (Table I).

The predicted distribution of $R$. neglectus covered mainly the cerrado of Central Brazil, but the models also revealed moderate to high predictive agreement of presence of this species in transitional areas, such as cerradocaatinga [western Bahia (BA)], cerrado-Pantanal [Mato Grosso do Sul (MS)], cerrado-Amazon (northern areas of Mato Grosso and Tocantins), cerrado-Paraná interior forests [western São Paulo (SP)] and cerrado-Maranhão babaçu forests (north of MA and PI), as shown in Fig. $1 \mathrm{~A}$. The potential distribution of $R$. nasutus covered the Northeastern Region of Brazil in the semi-arid caatinga and the Maranhão babaçu forests. However, the prediction maps of $R$. nasutus indicated areas of potential occurrence for this species in Central Brazil (Fig. 1B).

ENM of $R$. neglectus and $R$. nasutus supports potential areas of co-occurrence for these species in the Maranhão babaçu forests and in caatinga/cerrado transitional areas, mainly in PI (Fig. 1A, B). However, these species showed statistically different values for the environmental variables of their occurrence areas (Table II). Clear ecological niche differences between these species were observed. $R$. nasutus occurred more in warmer and drier areas than $R$. neglectus (Fig. 2A). Moreover, the occurrence areas of $R$. neglectus showed the highest values of altitude and NDVI (Table II, Fig. 2B).

In the multivariate analysis, including all environmental variables from the occurrence areas for $R$. neglectus and $R$. nasutus, the first two principal components (PC) summarised $66 \%$ of the environmental variance and also showed clear niche differences between these species (Fig. 2C). PC1 explained most of the total variation and was correlated with altitude and temperature variables, mainly temperature in the coldest and driest months. PC2 explained 19\% of the environmental variance and was correlated with NDVI and precipitation variables (Table III). Low values of precipitation/NDVI combined with high values of temperature in the coldest and driest months distinguish the ecological niche of $R$. nasutus from that of $R$. neglectus.

\section{TABLE I}

Statistical parameters for the 10 models in the best subset selection outcoming from ecological niche modeling of Rhodnius neglectus and Rhodnius nasutus

\begin{tabular}{lcccc}
\hline Species & $\chi^{2}$ & $\mathrm{p}$ & Commission $^{a}$ & Omission $^{b}$ \\
\hline R. neglectus & $57.7-77.2$ & $<0.01$ & $17.4-24.9$ & $0-16.6$ \\
R. nasutus & $154.4-365.0$ & $<0.01$ & $5.0-11.4$ & $0-9.5$
\end{tabular}

$\overline{a \text { : percentage of the predicted area that exceeds the recorded }}$ occurrence; $b$ : percentage of test points that were predicted absent, but are presence records of the species. Values present the range of the 10 models in the best subset selection; p: probability that a random prediction has the same number of correct predicted points as the one generated by DesktopGarp application (version 1.1.6); $\chi^{2}$ : chi-square statistics. 

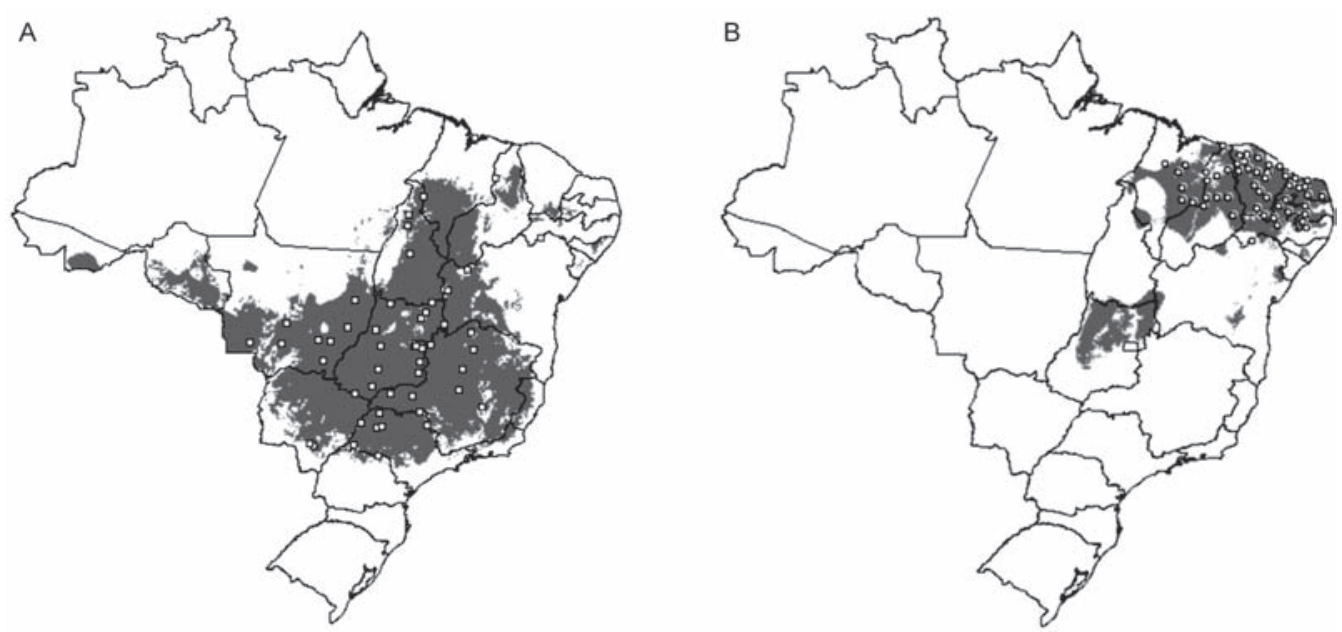

Fig. 1: predicted geographical distribution of Rhodnius neglectus (A: after Gurgel-Gonçalves \& Cuba 2009) and R. nasutus (B) in Brazil based on ecological niche modelling (Genetic Algorithm for Rule-set Production). The blank areas represent the absence predicted by the models. The symbols represent the occurrence records of $R$. neglectus (white squares) and $R$. nasutus (white circles) used in modeling. Grey areas represent coincidence of 5-10 best models (moderate to high predictive agreement of presence).

TABLE II

Mean, standard deviations and $t$-test results of some ecological variables from the occurrence areas of Rhodnius neglectus and Rhodnius nasutus in Brazil

\begin{tabular}{lccrr}
\hline Variables & R. neglectus & $R$. nasutus & $t$ - test & p \\
\hline Annual mean temperature $\left({ }^{\circ} \mathrm{C}\right)$ & $23.6 \pm 1.8$ & $25.7 \pm 1.7$ & 5.6 & $<0.01$ \\
Annual precipitation $(\mathrm{mm})$ & $1448 \pm 267$ & $968 \pm 319$ & -7.9 & $<0.01$ \\
Mean altitude (masl) & $528 \pm 280$ & $255 \pm 215$ & -5.6 & $<0.01$ \\
Normalized difference vegetation index & $744 \pm 26$ & $716 \pm 42$ & -4.0 & $<0.01$ \\
\hline
\end{tabular}

\section{DISCUSSION}

The use of the ENM approach to analyse the predicted geographical distribution of triatomines has been increasing in recent years (Costa et al. 2002, Gorla 2002, Peterson et al. 2002, Rodriguero \& Gorla 2004, López-Cárdenas et al. 2005, Sandoval-Ruiz et al. 2008, Arboleda et al. 2009, Gurgel-Gonçalves \& Cuba 2009, Gurgel-Gonçalves \& Silva 2009, Ibarra-Cerdeña et al. 2009). These predictions have yielded ecological and biogeographical knowledge regarding triatomines that may lead to new vector-control and surveillance strategies for Chagas disease.

The geographical distribution of R. nasutus reviewed in the present study included occurrence records from $\mathrm{PE}$ and BA and was wider than that recorded by Carcavallo et al. (1999). We also updated the alti-latitudinal distribution and described the ecological niche for this species. The association between $R$. nasutus and palm tree species may also explain the distribution patterns observed. $R$. nasutus occurs mainly in the carnauba wax palm Copernicia prunifera (Mill.) HE Moore, where it feeds mainly on birds (Lent \& Wygodzinsky 1979, Pinto \& Bento 1986, Carcavallo et al. 1998, Sarquis et al. 2004). However, $R$. nasutus inhabits other palm tree species such as Attalea speciosa Mart. and Syagrus olera- cea (Mart.) Becc., which have a wide distribution in the caatinga and cerrado biomes (Bento et al. 1992, Dias et al. 2008). Moreover, the colonisation of this triatomine in another tree species (Licania rigida Benth.) was reported by Lima and Sarquis (2008). These authors also suggest that environmental damage is facilitating the ability of $R$. nasutus to colonise other trees besides palms. The potential distributions of these tree species should be investigated and compared with $R$. nasutus' distribution in future studies to better understand these associations.

The predicted distribution of $R$. neglectus was similar to the one presented by Gurgel-Gonçalves and Cuba (2009), but in the present study we increased the range of the predicted area in Southwestern Brazil after including records from MS and SP. Although R. neglectus occurs mainly in the cerrado biome and $R$. nasutus in the drier caatinga, potential distribution areas of $R$. neglectus in the caatinga and $R$. nasutus in the cerrado were observed. The presence of $R$. neglectus in caatinga is already registered (Abad-Franch et al. 2009, Gurgel-Gonçalves \& Cuba 2009), but available distributional data do not show the presence of $R$. nasutus in the core area of the cerrado; all known records of Rhodnius in this region are due to R. neglectus (Lent \& Wygodzinsky 1979, Carcavallo et al. 1999, Galvão et al. 2003, Gurgel-Gonçalves et al. 2003, 


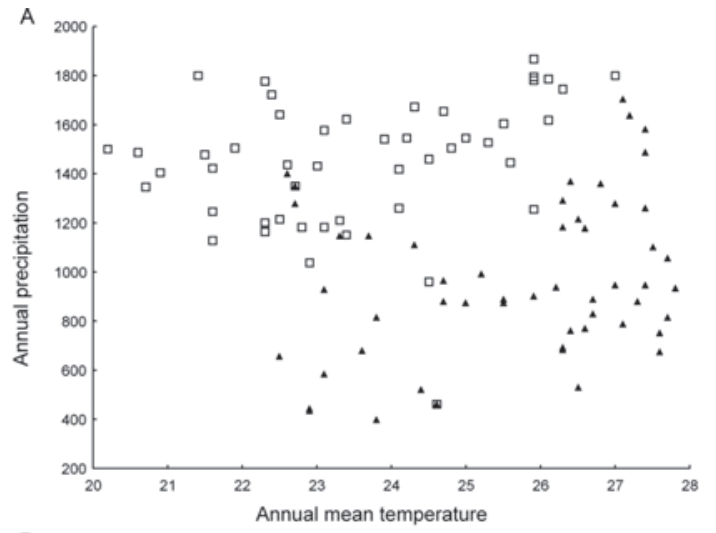

B
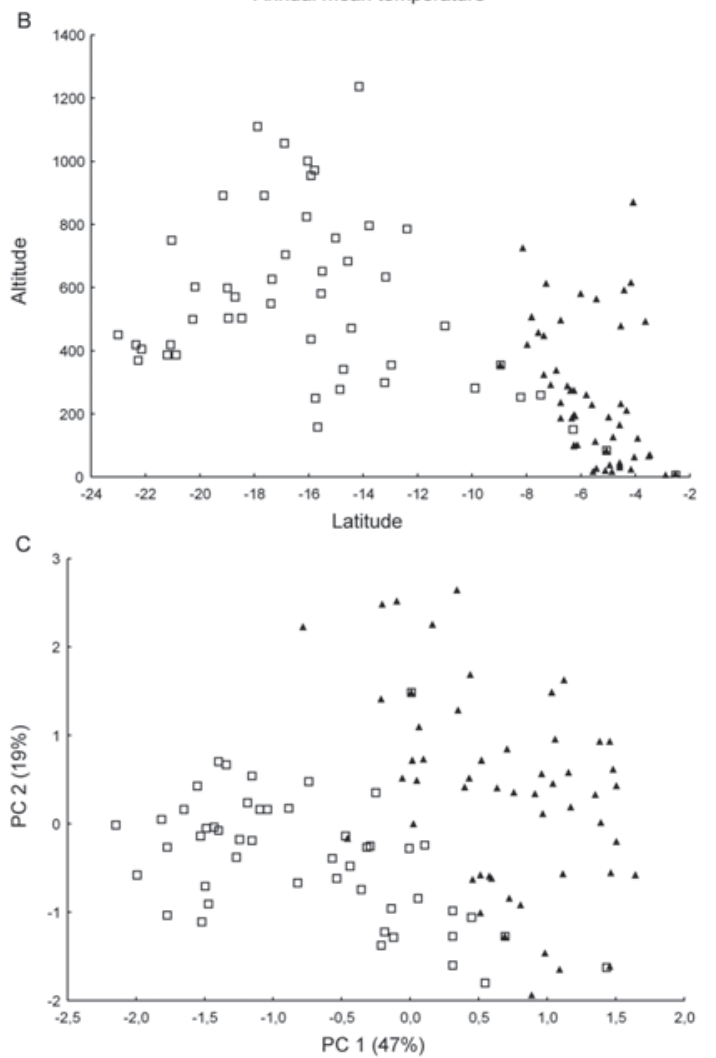

Fig 2: ecological niche differentiation between Rhodnius neglectus (squares) and Rhodnius nasutus (triangles) occurrence areas. A: annual mean temperature and precipitation values; B: alti-latitudinal distribution; C: component scores of the first two components from the principal component analysis (PC1 and PC2) for all environmental variables from the occurrence areas of $R$. neglectus and $R$. nasutus.

2004, 2008). According to Anderson et al. (2003), this overprediction error in ENM approaches derives from potentially habitable regions correctly predicted as presence, but that cannot be demonstrated as such because there is no occurrence record of the species there. Indeed, the predicted areas of R. nasutus in Central Brazil (mainly in state of Goiás) should be related to low precipitation values in the dry season. The absence of $R$. nasutus in Central Brazil may have various causes, including historical restrictions (e.g., geographic barriers and/or lack
TABLE III

Variables correlation with the first two principal components (PC1 and PC2) which reflects the importance of the environmental variables used do produce the ecological niche models of Rhodnius neglectus and Rhodnius nasutus

\begin{tabular}{lcc}
\hline Variables & PC1 & PC2 \\
\hline Normalized difference vegetation index & -0.18 & $-0.78^{a}$ \\
Altitude & $-0.80^{a}$ & 0.21 \\
Annual mean temperature & $0.89^{a}$ & -0.20 \\
Mean diurnal range & -0.57 & -0.37 \\
Isothermality & 0.62 & 0.01 \\
Temperature seasonality & $-0.75^{a}$ & 0.14 \\
Max. temperature of warmest month & $0.71^{a}$ & -0.38 \\
Min. temperature of coldest month & $0.98^{a}$ & 0.00 \\
Temperature annual range & $-0.71^{a}$ & -0.33 \\
Mean temperature of wettest quarter & $0.74^{a}$ & -0.24 \\
Mean temperature of driest quarter & $0.97^{a}$ & -0.15 \\
Mean temperature of warmest quarter & $0.85^{a}$ & -0.28 \\
Mean temperature of coldest quarter & $0.95^{a}$ & -0.26 \\
Annual precipitation & -0.33 & $-0.86^{a}$ \\
Precipitation of driest month & -0.02 & $-0.79^{a}$ \\
Precipitation of wettest month & -0.54 & -0.31 \\
Precipitation seasonality & 0.68 & 0.40 \\
Precipitation of wettest quarter & -0.07 & $-0.83^{a}$ \\
Precipitation of driest quarter & -0.53 & -0.35 \\
Precipitation of warmest quarter & -0.63 & -0.16 \\
Precipitation of coldest quarter & 0.43 & -0.42 \\
\hline
\end{tabular}

a: correlation $>0.7$.

of sufficient dispersal opportunities) and biotic interactions (such as competition with related species; e.g., $R$. neglectus). By examining the congruence or discordance between predicted and actual distributions, it is possible to evaluate the potential role of ecological and historical factors in determining a species' geographical distribution (Anderson et al. 2002).

The temperature, altitude, NDVI and precipitation values of $R$. neglectus and $R$. nasutus occurrence areas were compared and our results showed clear ecological niche differences between these species. PCA was also useful for measuring niche amplitude for each species, as previously reported for North American triatomines (Ibarra-Cerdeña et al. 2009). The maximum variation in niche amplitude occurred along the first axis (PC1), mainly associated with a temperature gradient. Moreover, a precipitation-humidity gradient was observed along the second axis (PC2). Our results support the hypothesis that the warmest and driest areas of Northeastern Brazil produce ideal conditions for $R$. nasutus occurrence. In contrast, the coldest areas with the highest altitude and NDVI values seem to be favourable for $R$. neglectus.

Other studies addressing the influence of climatic variables on triatomine distribution have also showed ecological niche differences between triatomine species (Costa et al. 2002, Sandoval-Ruiz et al. 2008, Arboleda et al. 2009). For example, the vapour pressure deficit minimum was the principal variable among the nine 
most important to describe the distribution of Rhodnius pallescens, which is in agreement with its stenohydric status (Arboleda et al. 2009).

Thus, the distribution of Rhodnius species may be explained by various climatic factors. Apparently, the level of humidity is one of the main factors separating species of humid environments (most species of Rhodnius) from those of dry environments, such as $R$. neglectus and especially $R$. nasutus. Further studies analysing the influence of environmental variables on the geographical distribution of all 16 known Rhodnius species should reinforce this hypothesis. Finally, these studies should have implications for the surveillance of Chagas disease vectors, because there is evidence that triatomine household infestation is restricted to the driest regions (Abad-Franch \& Monteiro 2007, Sandoval Ruiz et al. 2008).

ENM of closely related species occurring in adjoining or slightly overlapping areas is useful for exploring the factors affecting the species' geographical distributions and for providing directional hypotheses that can be tested in future studies. Investigations at smaller spatial scales on the ecology of these species (e.g., microhabitat, feeding patterns), especially comparisons among populations occurring inside and outside the predicted overlap zone, should give conclusive results on the roles of competitive interactions and historical factors in shaping species distributions (Costa et al. 2008). Further comparative phylogeographical studies may also evaluate the role of demography and climatic events in shaping the diversity and distribution of $R$. neglectus and $R$. nasutus populations in South America. In Brazil, the predicted maps support potential areas of co-occurrence for these species in MA, PI, CE, PE, BA, state of Paraíba (PB) and state of Alagoas. There are occurrence records of $R$. neglectus and $R$. nasutus sharing ecotopes in the same localities in PI (Bento et al. 1992) and BA (AbadFranch et al. 2009). The same pattern may occur in other areas including the MA, PI, CE, PE and PB that have favourable macroenvironmental conditions for both species to occur. Such areas should be investigated to broadly compare the realised distribution with the one predicted by the models and to identify microenvironmental factors segregating these species.

Entomologists engaged in Chagas disease vector surveillance should be aware that the morphologically similar triatomines $R$. neglectus and $R$. nasutus can occur in the same localities of Northeastern Brazil, as predicted in our study. Thus, the identification of bugs in these areas should be improved by applying morphometrical (Gurgel-Gonçalves et al. 2008) and/or molecular (AbadFranch \& Monteiro 2005) methods.

\section{ACKNOWLEDGEMENTS}

To Ricardo B Machado, for providing the database compiled for analysis using GARP, to Karen Schmidt, for assistance in earlier methodological analysis, to Fábio Oliveira Alves, for great fieldwork assistance, and to César A Cuba Cuba, Fernando Abad-Franch, Fernando A Monteiro, Liléia Diotaiuti, Lourdes MA El-moor, Loureiro and Renato Caparroz, for suggestions on an preliminary versions of this manuscript.

\section{REFERENCES}

Abad-Franch F, Monteiro FA 2005. Molecular research and the control of Chagas disease vectors. An Acad Bras Cienc 77: 437-454.

Abad-Franch F, Monteiro FA 2007. Biogeography and evolution of Amazonian triatomines (Heteroptera: Reduviidae): implications for Chagas disease surveillance in humid forest ecoregions. Mem Inst Oswaldo Cruz 102: 57-70.

Abad-Franch F, Monteiro FA, Jaramillo NO, Gurgel-Gonçalves R, Dias FBS, Diotaiuti L 2009. Ecology, evolution and the long-term surveillance of vector-borne Chagas disease: A multi-scale appraisal of the tribe Rhodniini (Triatominae). Acta Trop 112: 159-177.

Anderson RP, Gómez-Laverde M, Peterson AT 2002. Geographical distributions of spiny pocket mice in South America: insights from predictive models. Global Ecol Biogeogr 11: 131-141.

Anderson RP, Lew D, Peterson AT 2003. Evaluating predictive models of species' distributions: criteria for selecting optimal models Ecol Model 162: 211-232.

Arboleda S, Gorla DE, Porcasi X, Saldaña A, Calzada J, Jaramillo N 2009. Development of a geographical distribution model of Rhodnius pallescens Barber, 1932 using environmental data recorded by remote sensing. Inf Genet Evol 9: 441-448.

Bento DNC, Farias LM, Godoy MF, Araújo JFP 1992. Epidemiologia da doença de Chagas na zona rural do município de TeresinaPiauí, Brasil. Rev Soc Bras Med Trop 25: 51-58.

Carcavallo RU, Curto de Casas SI, Sherlock I, Galíndez Girón I, Jurberg J, Galvão C, Mena Segura CA, Noireau F 1999. Geographical distribution and alti-latitudinal dispersion. In RU Carcavallo, I Galíndez Girón, J Jurberg, H Lent (eds.), Atlas of Chagas disease vectors in Americas, Vol. III, Fiocruz, Rio de Janeiro, p. 747-792.

Carcavallo RU, Rodríguez MEF, Salvatella R, Curto de Casas SI, Sherlock I, Galvão C, Rocha DS, Galíndez Girón, I, Arocha MAO, Martinez A, Rosa JA da, Canale DM, Farr TH, Barata JMS 1998. Habitat and related fauna. In RU Carcavallo, I Galíndez Girón, J Jurberg, H Lent (eds.), Atlas of Chagas disease vectors in Americas, Vol. II, Fiocruz, Rio de Janeiro, p. 561-620.

Costa GC, Wolfe C, Shepard DB, Caldwell JP, Vitt LJ 2008. Detecting the influence of climatic variables on species distributions: a test using GIS niche-based models along a steep longitudinal environmental gradient. J Biogeogr 35: 637-646.

Costa J, Peterson AT, Beard CB 2002. Ecologic niche modeling and differentiation of populations of Triatoma brasiliensis Neiva, 1911, the most important Chagas' disease vector in Northeastern Brazil (Hemiptera: Reduviidae: Triatominae). Am J Trop Med Hyg 67: 516-520.

Dias FBS, Bezerra CM, Machado EMM, Casanova C, Diotaiuti L 2008. Ecological aspects of Rhodnius nasutus Stål, 1859 (Hemiptera: Reduviidae: Triatominae) in palms of the Chapada do Araripe in Ceará, Brazil. Mem Inst Oswaldo Cruz 103: 824-830.

Foottit RG, Sorensen JT 1992. Ordination methods: their contrast to clustering and cladistic techniques. In JT Sorensen, R Foottit (eds.), Ordination in the study of morphology, evolution and systematics of insects: applications and quantitative genetic rationales, Elsevier Science Publishing Inc, New York, p. 1-10.

Galvão C, Carcavallo R, Rocha DS, Jurberg J 2003. A checklist of the current valid species of the subfamily Triatominae, Jeannel, 1919 (Hemiptera: Reduviidae) and their geographic distribution. Zootaxa 202: 1-36.

Gorla DE 2002. Variables ambientales registradas por sensores remotos como indicadores de la distribución geográfica de Triatoma infestans. Ecol Austral 12: 117-127. 
Guhl F, Pinto N, Aguilera G 2009. Sylvatic triatominae: a new challenge in vector control transmission. Mem Inst Oswaldo Cruz 104 (Suppl. I): 71-75.

Gurgel-Gonçalves R, Abad-Franch F, Ferreira JBC, Santana DB, Cuba CAC 2008. Is Rhodnius prolixus (Triatominae) invading houses in Central Brazil? Acta Trop 107: 90-98.

Gurgel-Gonçalves R, Cuba CAC 2009. Predicting the potential geographical distribution of Rhodnius neglectus (Hemiptera: Reduviidae) based on ecological niche modeling. J Med Entomol 46: 952-960.

Gurgel-Gonçalves R, Duarte MA, Ramalho ED, Romaña CA, Cuba CAC 2004. Distribuição espacial de populações de Triatominae (Hemíptera: Reduviidae) em palmeiras da espécie Mauritia flexuosa no Distrito Federal, Brasil. Rev Soc Bras Med Trop 37: 241-247.

Gurgel-Gonçalves R, Palma ART, Menezes MNA, Leite RN, Cuba CAC 2003. Sampling Rhodnius neglectus (Triatominae) in Mauritia flexuosa palm trees (Arecaceae): a field study in the Brazilian Savanna. Med Vet Entomol 17: 347-349.

Gurgel-Gonçalves R, Silva RB 2009. Analysis of the geographical distribution of Psammolestes Bergroth (Heteroptera: Reduviidae) in South America with new records of Psammolestes tertius Lent \& Jurberg. Zootaxa 2033: 41-48.

Ibarra-Cerdeña CN, Sánchez-Cordero V, Peterson AT, Ramsey JM 2009. Ecology of North American Triatominae. Acta Trop 110: 178-186.

Lent H 1948. O gênero Rhodnius Stål, 1859 (Hemiptera: Reduviidae). Rev Bras Biol 8: 297-339.

Lent H 1954. Comentários sobre o gênero Rhodnius Stål com descrição de uma nova espécie do Brasil (Hemíptera: Reduviidae). Rev Bras Biol 14: 237-247.

Lent H, Wygodzinsky P 1979. Revision of the triatominae (Hemiptera: Reduviidae) and their significance as vectors of Chagas disease. Bull Am Mus Nat Hist 163: 520-529.

Lima MM, Sarquis O 2008. Is Rhodnius nasutus (Hemiptera; Reduviidae) changing its habitat as a consequence of human activity? Parasitol Res 102: 797-800.
López-Cárdenas J, González-Bravo FE, Salazar-Schettino PM, Gallaga-Solorzano JC, Ramírez-Barba E, Martínez-Mendez J, Sánchez-Cordero V, Peterson AT, Ramsey JM 2005. Fine-scale predictions of distributions of Chagas disease vectors in the state of Guanajuato, Mexico. J Med Entomol 42: 1068-1081.

Lucena DT, Lima-Borba H 1977. Panstrongylus megistus leucofasciatus Lucena, 1959 e Rhodnius nasutus Stål, 1859 (Hemiptera: Triatominae) em Pernambuco, Brasil. Rev Inst Med Trop Sao Paulo 19: 332-334.

Peterson AT 2006. Ecologic niche modeling and spatial patterns of disease transmission. Emerg Infect Dis 12: 1822-1825.

Peterson AT, Sánchez-Cordero V, Beard CB, Ramsey JM 2002. Ecologic niche modelling and potential reservoirs for Chagas disease, Mexico. Emerg Infect Dis 8: 662-667.

Pinto AS, Bento DNC 1986. The palm tree Copernicia cerifera (Carnaúba) as an ecotope of Rhodnius nasutus in rural areas of the state of Piauí, Northeastern Brazil. Rev Soc Bras Med Trop 19: 243-245.

Rodriguero MS, Gorla DE 2004. Latitudinal gradient in species richness of the New World Triatominae (Reduviidae). Global Ecol Biogeogr 13: 75-84.

Sandoval-Ruiz CA, Zumaquero-Rios JL, Rojas-Soto OR 2008. Predicting geographic and ecological distributions of triatomine species in the southern Mexican state of Puebla using ecological niche modeling. J Med Entomol 45: 540-546.

Sarquis O, Borges-Pereira J, Mac Cord JR, Gomes TF, Cabello PH, Lima MM 2004. Epidemiology of Chagas disease in Jaguaruana, Ceará. I. Presence of triatomines and index of Trypanosoma cru$z i$ infection in four localities of a rural area. Mem Inst Oswaldo Cruz 99: 263-270.

Silveira AC, Feitosa VR, Borges R 1984. Distribuição de triatomíneos capturados no ambiente domiciliar no período de 1975/83, Brasil. Rev Bras Malariol D Trop 39: 15-312.

Stockwell DRB, Peters D 1999. The GARP modeling system: problems and solutions to automated spatial prediction. Int J Geog Inf Sci 13: 143-158.

Tsoar A, Allouche O, Steinitz O, Rotem D, Kadm R 2007. A comparative evaluation of presence only methods for modelling species distribution. Divers Distrib 13: 397-405. 